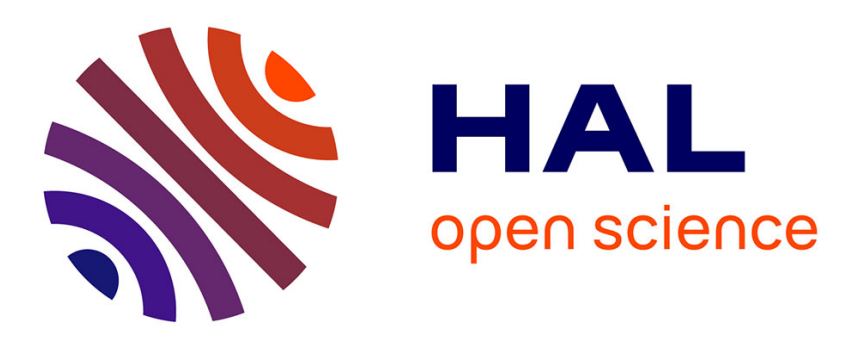

\title{
Enhancement of the photoprotection and nanomechanical properties of polycarbonate by deposition of thin ceramic coatings
}

B Mailhot, Agnès Rivaton, Jean-Luc Gardette, A Moustaghfir, E Tomasella, M Jacquet, X.-G Ma, K Komvopoulos

\section{To cite this version:}

B Mailhot, Agnès Rivaton, Jean-Luc Gardette, A Moustaghfir, E Tomasella, et al.. Enhancement of the photoprotection and nanomechanical properties of polycarbonate by deposition of thin ceramic coatings. Journal of Applied Physics, 2006, 99, pp.104310 - 254102. hal-00131378

\section{HAL Id: hal-00131378 \\ https://hal.science/hal-00131378}

Submitted on 10 Dec 2014

HAL is a multi-disciplinary open access archive for the deposit and dissemination of scientific research documents, whether they are published or not. The documents may come from teaching and research institutions in France or abroad, or from public or private research centers.
L'archive ouverte pluridisciplinaire HAL, est destinée au dépôt et à la diffusion de documents scientifiques de niveau recherche, publiés ou non, émanant des établissements d'enseignement et de recherche français ou étrangers, des laboratoires publics ou privés. 


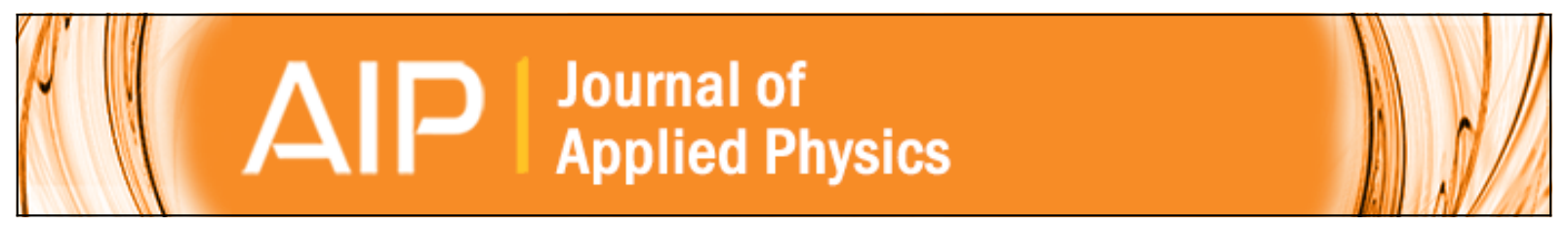

\section{Enhancement of the photoprotection and nanomechanical properties of polycarbonate by deposition of thin ceramic coatings}

B. Mailhot, A. Rivaton, J.-L. Gardette, A. Moustaghfir, E. Tomasella, M. Jacquet, X.-G. Ma, and K. Komvopoulos

Citation: Journal of Applied Physics 99, 104310 (2006); doi: 10.1063/1.2197030

View online: http://dx.doi.org/10.1063/1.2197030

View Table of Contents: http://scitation.aip.org/content/aip/journal/jap/99/10?ver=pdfcov

Published by the AIP Publishing

\section{Articles you may be interested in}

Nanomechanical and optical properties of highly a-axis oriented AIN films

Appl. Phys. Lett. 101, 254102 (2012); 10.1063/1.4772204

Synthesis of zinc oxide powder as function of precursor concentration and their photo catalytic activity test AIP Conf. Proc. 1476, 339 (2012); 10.1063/1.4751624

Study of photocatalytic activity of TiO 2 thin films prepared in various $\mathrm{Ar} / \mathrm{O} 2$ ratio and sputtering gas pressure J. Vac. Sci. Technol. A 25, 912 (2007); 10.1116/1.2717194

Investigation of the nanostructure and wear properties of physical vapor deposited $\mathrm{CrCuN}$ nanocomposite coatings

J. Vac. Sci. Technol. A 23, 423 (2005); 10.1116/1.1875212

Microstructure of $\alpha$-alumina thin films deposited at low temperatures on chromia template layers

J. Vac. Sci. Technol. A 22, 117 (2004); 10.1116/1.1636157
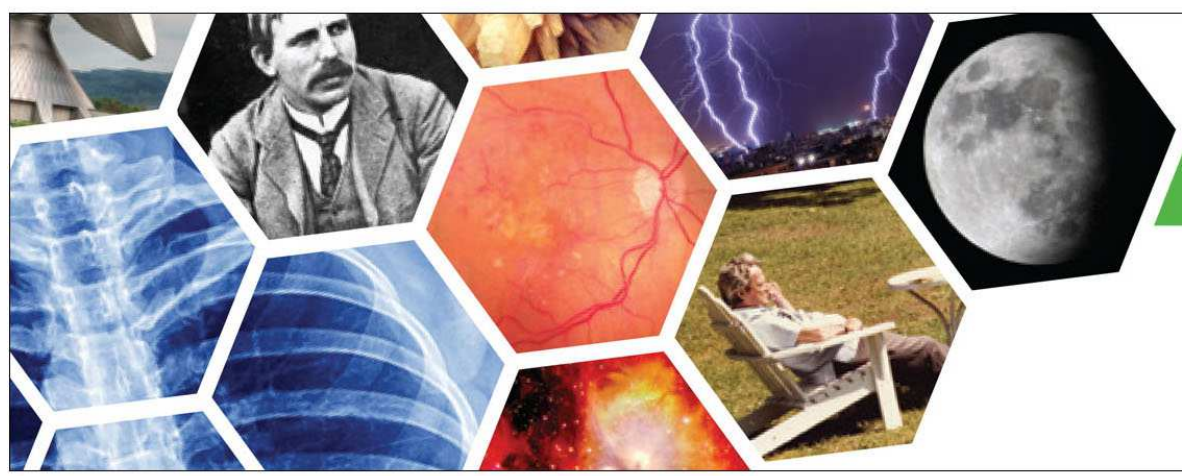

\section{SUBSCRIBE TO \\ physics today}




\title{
Enhancement of the photoprotection and nanomechanical properties of polycarbonate by deposition of thin ceramic coatings
}

\author{
B. Mailhot, A. Rivaton, and J.-L. Gardette \\ Laboratoire de Photochimie Moléculaire et Macromoléculaire, UMR CNRS 6505, Université Blaise Pascal \\ (Clermont-Ferrand), F-63177 Aubière Cedex, France
}

\author{
A. Moustaghfir, E. Tomasella, and M. Jacquet \\ Laboratoire des Matériaux Inorganiques, UMR CNRS 6002, Université Blaise Pascal \\ (Clermont-Ferrand), F-63177 Aubière Cedex, France \\ X.-G. Ma and K. Komvopoulos ${ }^{\text {a) }}$ \\ Department of Mechanical Engineering, University of California, Berkeley, California 94720
}

(Received 1 July 2005; accepted 17 March 2006; published online 26 May 2006)

\begin{abstract}
The chemical reactions resulting from ultraviolet radiation produce discoloration and significant changes in the surface properties of polycarbonate (PC). To prevent photon absorption from irradiation and oxygen diffusion and to enhance the surface nanomechanical properties of $\mathrm{PC}$, thin ceramic coatings of $\mathrm{ZnO}$ and $\mathrm{Al}_{2} \mathrm{O}_{3}$ (both single- and multi-layer) were deposited on bulk PC by radio-frequency magnetron sputtering. The samples were irradiated at wavelengths greater than $300 \mathrm{~nm}$, representative of outdoor conditions. Despite the effectiveness of $\mathrm{ZnO}$ to protect $\mathrm{PC}$ from irradiation damage, photocatalytic oxidation at the $\mathrm{PC} / \mathrm{ZnO}$ interface was the limiting factor. To overcome this deficiency, a thin $\mathrm{Al}_{2} \mathrm{O}_{3}$ coating was used both as intermediate and top layer because of its higher hardness and wear resistance than $\mathrm{ZnO}$. Therefore, $\mathrm{PC} / \mathrm{Al}_{2} \mathrm{O}_{3} / \mathrm{ZnO}, \mathrm{PC} / \mathrm{ZnO} / \mathrm{Al}_{2} \mathrm{O}_{3}$, and $\mathrm{PC} / \mathrm{Al}_{2} \mathrm{O}_{3} / \mathrm{ZnO} / \mathrm{Al}_{2} \mathrm{O}_{3}$ layered media were fabricated and their photodegradation properties were examined by infrared and ultraviolet-visible spectroscopy. It was found that the photocatalytic activity at the $\mathrm{PC} / \mathrm{ZnO}$ interface was reduced in the presence of the intermediate $\mathrm{Al}_{2} \mathrm{O}_{3}$ layer that limited the oxygen permeability. Nanomechanical experiments performed with a surface force apparatus revealed that the previous coating systems enhanced both the surface nanohardness and the elastic modulus and reduced the coefficient of friction in the order of $\mathrm{ZnO}, \mathrm{Al}_{2} \mathrm{O}_{3}$, and $\mathrm{Al}_{2} \mathrm{O}_{3} / \mathrm{ZnO} / \mathrm{Al}_{2} \mathrm{O}_{3}$. Although irradiation increased the nanohardness and the elastic modulus of PC, the irradiation effect on the surface mechanical properties of ceramic-coated PC was secondary.

(c) 2006 American Institute of Physics. [DOI: 10.1063/1.2197030]
\end{abstract}

\section{INTRODUCTION}

Polycarbonate $(\mathrm{PC})$ is increasingly used to replace various structural materials, such as metals and glasses, because of its high toughness, good transparency, and relatively low density. However, absorption of ultraviolet (UV) radiation from the exposure to sunlight induces chemical reactions that cause discoloration, significant changes in the surface mechanical properties, and embrittlement. The chemical mechanisms responsible for the degradation of PC by UV irradiation have been investigated extensively. ${ }^{1-3}$ When PC is exposed to the sunlight, the aromatic carbonate groups of the monomer units absorb short-wavelength energy in the near-UV range. The absorbed energy promotes the rupture of the covalent bonds, resulting in photolytic and photooxidative reactions.

Several approaches have been used to minimize the effect of photoaging. A traditional method is to fortify the polymer with UV-absorbing additives. These colorless UV filters absorb the incident UV light that damages the polymer and are transparent to the visible light. The UV energy ab-

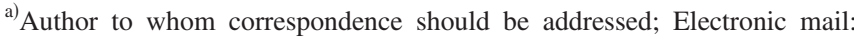
kyriakos@me.berkeley.edu
}

sorbed by the stabilizer must be dissipated without producing reactive species. However, the efficiency of the UV absorbers decreases when photodegradation occurs as a result of the direct absorption of sunlight radiations by intrinsic chromophoric polymer groups, such as those in aromatic polymers. This effect is a direct result of the Beer-Lambert law. Since the radiation is mostly absorbed by the polymer than the additives up to $\sim 40 \mu \mathrm{m}$ depths, effective photoprotection of the surface cannot be achieved. In addition, because UV absorbers act also as antioxidant compounds, ${ }^{4}$ upon fatigue-induced degradation they lead to the formation of color by-products.

Coating the polymer by a thick varnish that contains UV absorbers is another means of protecting polymer surfaces from photodegradation. Although this method eliminates the competition for absorption between the polymer and the UV absorbers, photo-oxidation of the varnish may lead to fatigue as in the case of the UV absorbers. ${ }^{5}$ Hence, the simultaneous decrease of the absorption of incident near-UV light by the coating and the interfacial adhesive strength affect negatively the durability of the polymer.

A more effective method to protect the polymer is by deposition of ceramic coatings that are transparent in the visible-light range. A ceramic coating provides a means of 
physically screening the incident radiation to reduce the undesirable effects of photochemical processes. In addition, the photo-oxidation rate decreases because the coating acts as an oxygen barrier. The effectiveness of this technique has been demonstrated in recent studies dealing with various polymers coated with $\mathrm{ZnO}$ and $\mathrm{TiO}_{2}$ coatings. ${ }^{6-8}$ However, $\mathrm{ZnO}$ promotes a photocatalytic activity ${ }^{9}$ through the formation of active species, resulting in photo-oxidative degradation of the polymer upon the reaction with water and/or oxygen. It has been argued that the most dominant reactive species are $\mathrm{HOO}^{\bullet}$ and $\mathrm{HO}^{\bullet}$ radicals. ${ }^{10,11}$ Because the photoactivity of $\mathrm{ZnO}$ leads to photocatalytic oxidation of the polymer at the interface, it is advantageous to first coat the polymer with a photocatalytically inactive ceramic layer, such as $\mathrm{Al}_{2} \mathrm{O}_{3}$. However, because $\mathrm{Al}_{2} \mathrm{O}_{3}$ does not provide a screening effect on the damaging UV radiation, it is necessary to synthesize a two-layer coating consisting of an $\mathrm{Al}_{2} \mathrm{O}_{3}$ underlayer and a $\mathrm{ZnO}$ top layer. Furthermore, because of the lower notch sensitivity and higher wear resistance of $\mathrm{Al}_{2} \mathrm{O}_{3}$ compared to $\mathrm{ZnO}$, a three-layer coating consisting of a $\mathrm{ZnO}$ layer sandwiched between two $\mathrm{Al}_{2} \mathrm{O}_{3}$ layers can be more effective in improving the surface nanomechanical properties of PC exposed to conditions conducive to photodegradation and wear than the single-layer coatings. In view of the small thickness of the protective coatings, the surface mechanical properties must be evaluated by the nanoindentation technique. Probebased techniques have been used extensively in recent years to obtain insight into contact surface phenomena. The simplicity of the nanoindentation technique and the capability to physically probe materials at very small scales have contributed to significant advances in nanoscale materials research.

The objective of this investigation was to determine the efficacy of an inactive $\mathrm{Al}_{2} \mathrm{O}_{3}$ layer deposited between a polymer and a ceramic surface layer to minimize photocatalytic oxidation. To accomplish this objective, the photochemical behaviors of various ceramic/polymer systems subjected to accelerated photoaging conditions were evaluated by infrared (IR) and UV-vis spectroscopy. In addition, nanoindentation and sliding experiments were performed with a surface force apparatus to determine the effect of photo-oxidation on the nanomechanical and tribological properties of the layered ceramic coatings.

\section{EXPERIMENTAL PROCEDURES}

\section{A. Specimens, irradiation experiments, and spectroscopy studies}

Antioxidant-free PC films (Technifilm) of thickness equal to $50 \mu \mathrm{m}$ were ultrasonically cleaned in ethanol before coating. The deposition of $\mathrm{ZnO}$ and $\mathrm{Al}_{2} \mathrm{O}_{3}$ layers was carried out in a sputtering unit (SCM 450, Alcatel) equipped with a $13.56 \mathrm{MHz}$ radio frequency generator. $\mathrm{ZnO}$ and $\mathrm{Al}_{2} \mathrm{O}_{3}$ targets of diameter $100 \mathrm{~mm}$ and $99.9 \%$ purity were fixed on cooled magnetron cathodes and were used to deposit the ceramic coatings. The PC substrates were placed at a distance of $90 \mathrm{~mm}$ from the targets. Before introducing the sputtering gas, the chamber was evacuated to a base pressure of less than $10^{-4} \mathrm{~Pa}$. Sputtering of $\mathrm{ZnO}$ was performed under deposition conditions resulting in maximum
PC photoprotection, ${ }^{12}$ i.e., argon (95\%)-oxygen (5\%) plasma, $1 \mathrm{~Pa}$ pressure, and $0.89 \mathrm{~W} / \mathrm{cm}^{2}$ power density. The $\mathrm{Al}_{2} \mathrm{O}_{3}$ coatings were deposited under sputtering conditions yielding dense microstructures possessing a low internal stress, i.e., pure argon plasma, $1 \mathrm{~Pa}$ pressure, and $1.27 \mathrm{~W} / \mathrm{cm}^{2}$ power density. The thickness of the sputtered coatings was measured by ellipsometry (wavelength $\lambda=632.8 \mathrm{~nm}$ ) and interferometry.

The specimens were irradiated at wavelengths greater than $300 \mathrm{~nm}$, representative of the sunlight radiation, using an equipment (SEPAP 12.24, Atlas) ${ }^{13,14}$ with mediumpressure mercury lamps operated under controlled temperature of $60{ }^{\circ} \mathrm{C}$ that causes accelerated photoaging. The resulting flux at the sample surface was $90 \mathrm{~W} / \mathrm{m}^{2}$. UV-vis and IR spectra were obtained with a computer-controlled spectrometer (UV-2101, Shimadzu) using an integrating sphere and a Fourier transform IR spectrometer (Magna-IR 760, Nicolet), respectively.

\section{B. Nanomechanical testing}

The nanomechanical behavior of the coated and uncoated PC samples was evaluated with a surface force apparatus consisting of an atomic force microscope (Nanoscope II, Digital Instruments) retrofitted with a force transducer (Triboscope, Hysitron, Inc.). Indentation experiments were performed with diamond tips of nominal radius of curvature equal to $\sim 117 \mathrm{~nm}$ (Berkovich) and $\sim 850 \mathrm{~nm}$ (conospherical), using triangular force functions with loading and unloading times both equal to $5 \mathrm{~s}$. Tuning of the electrostatic force constant of the transducer and tip-shape calibration were performed before testing. The tip calibration procedure was based on the method of Pharr et al. ${ }^{15}$ To determine the tip-shape function, different-depth indentations were produced on fused quartz of hardness and elastic modulus equal to $\sim 10$ and $\sim 73 \mathrm{GPa}$, respectively. The contact depth at maximum load and the slope of the unloading portion of the force-displacement curve determined at maximum load were respectively used to calculate the hardness and the reduced elastic modulus of the indented samples.

Sliding tests were performed with the $\sim 850 \mathrm{~nm}$ radius conospherical diamond tip. Wear tracks were produced by traversing the tip over the specimen surface by a distance of $2 \mu \mathrm{m}$ at a constant speed of $0.2 \mu \mathrm{m} / \mathrm{s}$, while increasing linearly the normal load from 3 to $250 \mu \mathrm{N}$. The coefficient of friction was obtained as the ratio of the lateral (friction) force to the instantaneous normal load. To avoid biasing of the measurements by neighboring wear tracks, the distance between sequential wear tracks was kept larger than $2 \mu \mathrm{m}$. Additional information for the testing procedure used in the nanoindentation and nanoscale sliding experiments can be found elsewhere. ${ }^{16}$

\section{RESULTS AND DISCUSSION}

\section{A. Photo-oxidation resistance}

Absorption of UV-light from the terrestrial solar radiation by PC occurs because light absorption in this material extends up to $\lambda=330 \mathrm{~nm}$. The resulting photodegradation for $\lambda>300 \mathrm{~nm}$ leads to significant modifications of the UV-vis 


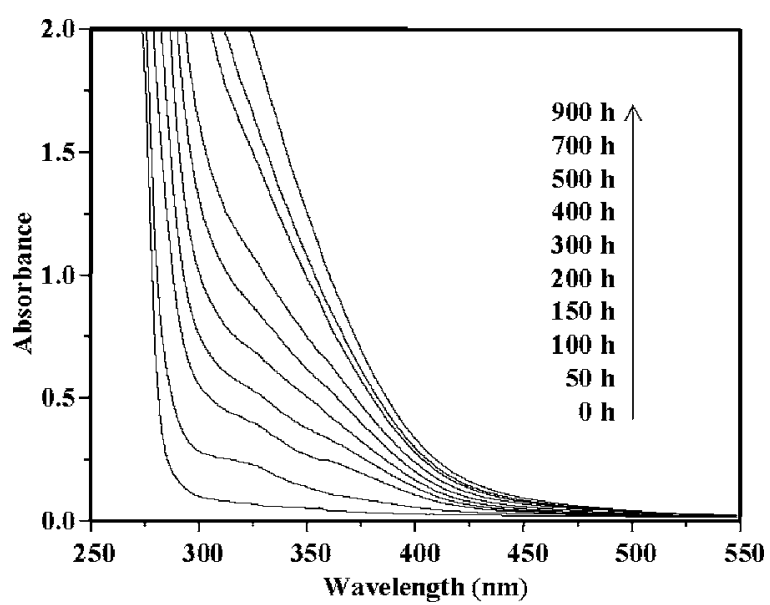

FIG. 1. Effect of time of exposure to polychromatic light on the UV-vis spectrum of PC. (The irradiation time increases from the lower curve toward the upper curve.)

and IR spectra. Figure 1 shows the effect of the irradiation time on the UV-vis absorption of PC. For a short exposure time, the maxima at $\sim 320$ and $\sim 355 \mathrm{~nm}$ are due to photoFries rearrangement of the carbonate units. ${ }^{1}$ With the increase of the irradiation time, these bands are rapidly overlapped by an unstructured absorption in the wavelength range of $\lambda<500 \mathrm{~nm}$. This absorption is attributed to a mixture of colored species produced from the photo-oxidation reactions of the aromatic rings, ${ }^{1-3}$ which are responsible for the yellow color of the irradiated PC.

Photo-oxidation of PC also results in significant changes in the IR spectrum (Fig. 2). In the hydroxyl absorption region $\left(3800-3000 \mathrm{~cm}^{-1}\right)$, the absorbance increased with the exposure time. The band centered at $\sim 3470 \mathrm{~cm}^{-1}$ is attributed to the formation of alcohols, acids, and hydroperoxides. ${ }^{1-3}$ The degradation rate is characterized by stable photoproducts produced during irradiation, as revealed by the changes in the UV-vis and IR spectra. Thus, photoinduced yellowing of PC is reflected by the absorbance increase in the UV-vis spectrum for $\lambda=400 \mathrm{~nm}$ (discoloration results from photolysis (photo-Fries) and photo-oxidation), while the photo-oxidation reactions in PC are indicated, among others, by the absorbance increase in the hydroxyl region $\left(\sim 3470 \mathrm{~cm}^{-1}\right)$ of the IR spectrum.

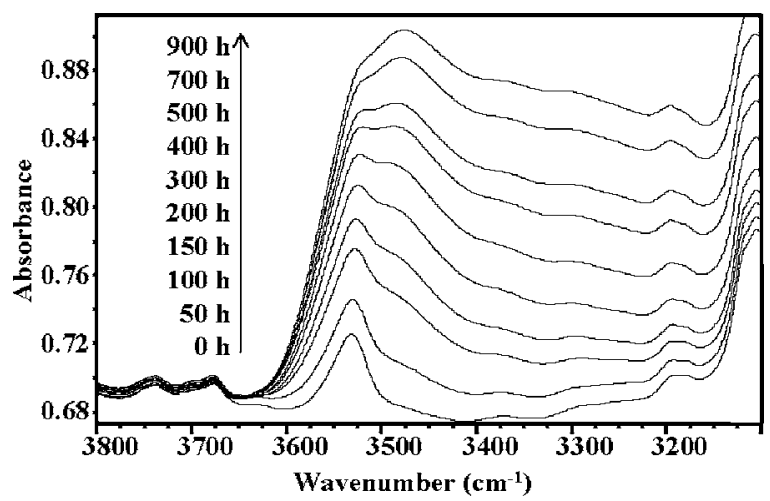

FIG. 2. Effect of time of exposure to polychromatic light on the IR spectrum of $\mathrm{PC}$ in the $3800-3000 \mathrm{~cm}^{-1}$ range. (The irradiation time increases from the lower curve toward the upper curve.)

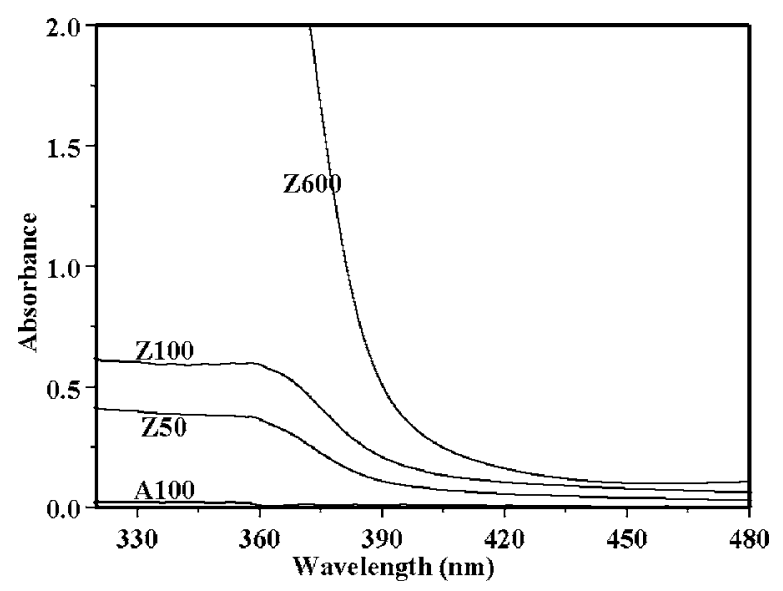

FIG. 3. UV-vis spectra of PC coated with 100-nm-thick $\mathrm{Al}_{2} \mathrm{O}_{3}(\mathrm{Al100})$ and 50-, 100-, and 600-nm-thick $\mathrm{ZnO}$ coatings (Z50, Z100, and Z600, respectively).

Both ceramic coatings used in this study possessed dense and columnar microstructures with a small excess in oxygen. The $\mathrm{Al}_{2} \mathrm{O}_{3}$ coatings were amorphous, whereas the $\mathrm{ZnO}$ coatings were crystallized in a hexagonal wurtzite phase. Both $\mathrm{Al}_{2} \mathrm{O}_{3}$ and $\mathrm{ZnO}$ coatings were under compressive internal stress of -0.14 and $-1.0 \mathrm{MPa}$, respectively. Figure 3 shows UV-vis spectra of $\mathrm{Al}_{2} \mathrm{O}_{3}$ and $\mathrm{ZnO}$ coatings of different thickness deposited on PC. It can be seen that the 100-nm-thick $\mathrm{Al}_{2} \mathrm{O}_{3}$ is totally transparent in this region, whereas the absorption of the $\mathrm{ZnO}$ coating exhibits strong thickness dependence. A previous study has shown that $\mathrm{ZnO}$ is an effective photodegradation barrier for PC. ${ }^{8}$ Figures $4(\mathrm{a})$ and 4(b) show that the absorbance change in the hydroxyl region $\left(\sim 3470 \mathrm{~cm}^{-1}\right)$ and $\lambda=400 \mathrm{~nm}$, respectively, increased with the irradiation time. A comparison of the UV-vis and IR results of PC coated with a single-layer $\mathrm{ZnO}$ coating shows that the photo-oxidation rate decreases with the increase of the coating thickness. This is mainly due to the direct absorption of radiation light, i.e., the screening effect of the coating. This effect is more pronounced for the thicker layer because both the grain size and the density of the $\mathrm{ZnO}$ coating increase with the thickness, hence leading to the decrease of the diffusion coefficient of oxygen. Therefore, a full protection was achieved with the $600-\mathrm{nm}$-thick $\mathrm{ZnO}$ coating, even for a $\sim 1000 \mathrm{~h}$ exposure to the accelerated photodegradation conditions.

The absorbance curves of the single-layer coatings shown in Fig. 4 indicate that the $\mathrm{Al}_{2} \mathrm{O}_{3}$ coating was less effective in preventing photodegradation than the $\mathrm{ZnO}$ coating. The IR curve for the 100-nm-thick $\mathrm{Al}_{2} \mathrm{O}_{3}$ coating [Fig. 4(a)] shows that the initial photo-oxidation rate was similar with that of PC. This implies that the formation rate of the hydroxyl products on the PC surface for irradiation time of less than $100 \mathrm{~h}$ was not affected by the $\mathrm{Al}_{2} \mathrm{O}_{3}$ coating. However, the $\mathrm{Al}_{2} \mathrm{O}_{3}$ coating was effective in reducing the longterm oxidation rate of PC. A similar trend, although less pronounced, is demonstrated by the UV-vis curve [Fig. 4(b)], i.e., the efficiency of $\mathrm{Al}_{2} \mathrm{O}_{3}$ to prevent yellowing was observed only after prolonged exposure to irradiation. These results can be attributed to both photolytic and photooxidative reactions. The UV-vis spectrum of the $\mathrm{Al}_{2} \mathrm{O}_{3}$ coat- 

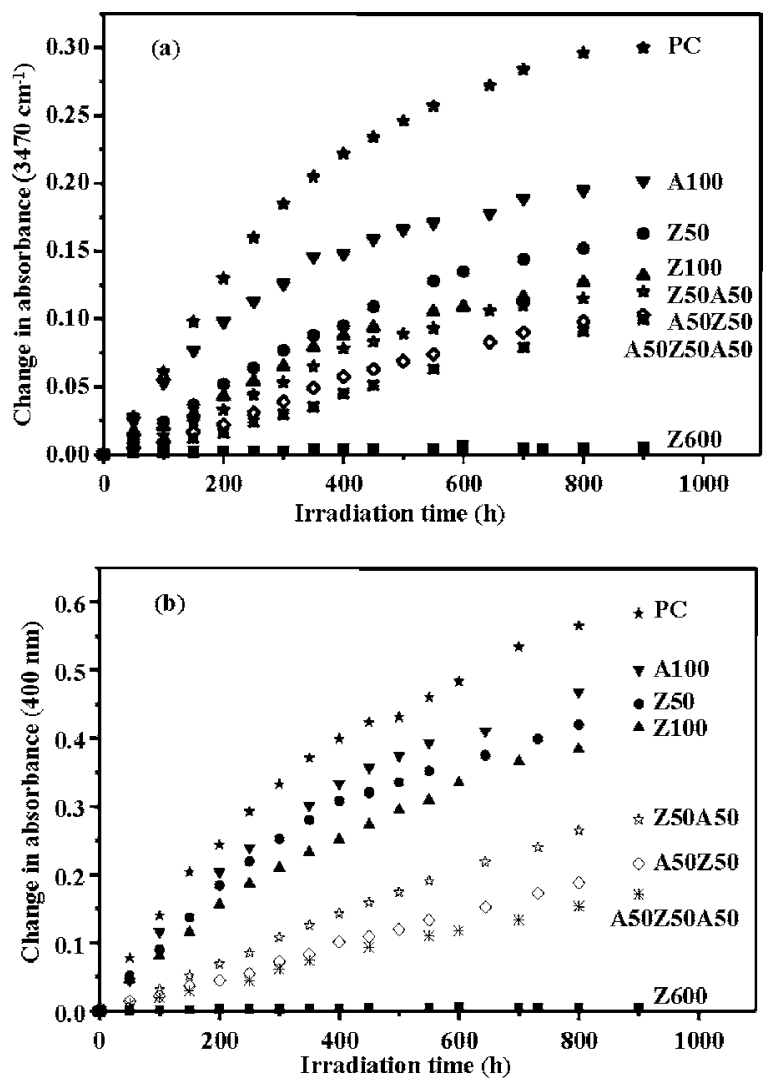

FIG. 4. Change in absorbance determined from (a) IR $\left(3470 \mathrm{~cm}^{-1}\right)$ and (b) UV-vis $(400 \mathrm{~nm})$ spectra vs irradiation time for PC coated with single- and multi-layer coatings of $\mathrm{ZnO}$ and $\mathrm{Al}_{2} \mathrm{O}_{3}$ of different thickness. (The $\mathrm{ZnO}$ and $\mathrm{Al}_{2} \mathrm{O}_{3}$ coatings are denoted by $Z$ and $A$, respectively, and the numbers indicate the corresponding layer thickness in nanometers.)

ing shown in Fig. 3 indicates that this material cannot protect the polymer against incident radiation. Consequently, the $\mathrm{Al}_{2} \mathrm{O}_{3}$ layer did not inhibit photo-Fries rearrangement, a process that does not depend on the presence of oxygen. However, the subsequent oxidative reactions that were initiated by photo-Fries products were inhibited because $\mathrm{Al}_{2} \mathrm{O}_{3}$ is an oxygen barrier. Therefore, while $\mathrm{Al}_{2} \mathrm{O}_{3}$ did not suppress the photolytic process, it was effective in reducing the extent of oxidative reactions because of its impermeability to oxygen.

To explore other means of further enhancing the photooxidation resistance of PC, UV-vis and IR spectra were obtained from samples of PC with two-layer $\left(\mathrm{Al}_{2} \mathrm{O}_{3} / \mathrm{ZnO}\right.$ and $\left.\mathrm{ZnO} / \mathrm{Al}_{2} \mathrm{O}_{3}\right)$ and three-layer $\left(\mathrm{Al}_{2} \mathrm{O}_{3} / \mathrm{ZnO} / \mathrm{Al}_{2} \mathrm{O}_{3}\right)$ coatings, and the corresponding absorbance changes in the hydroxyl region $\left(\sim 3470 \mathrm{~cm}^{-1}\right)$ and $\lambda=400 \mathrm{~nm}$ were contrasted with those of the single-layer coatings. For degradation to occur within a reasonable irradiation time, the thickness of the $\mathrm{ZnO}$ and $\mathrm{Al}_{2} \mathrm{O}_{3}$ layers was fixed at $50 \mathrm{~nm}$. Figure 4 shows IR and $\mathrm{UV}$-vis results for the multi-layer coatings revealing the rates of hydroxyl product formation and yellowing. Table I gives the initial oxidation rates obtained after exposure to the irradiation conditions for $100 \mathrm{~h}$. A comparison of the data for $A 100$ and $Z 100$ shows that the oxidation resistance provided by the $\mathrm{Al}_{2} \mathrm{O}_{3}$ coating was less than that of the $\mathrm{ZnO}$ coating. For a fixed coating thickness (i.e., $A 100, Z 100, Z 50 A 50$, and A50Z50), a significant decrease in the photocatalytic oxidation of $\mathrm{PC}$ at the $\mathrm{PC} / \mathrm{ZnO}$ interface was observed in the presence of an intermediate $\mathrm{Al}_{2} \mathrm{O}_{3}$ layer.
TABLE I. Initial oxidation rate (100 $\mathrm{h}$ of exposure to irradiation) determined from the increase of the absorbance at $3470 \mathrm{~cm}^{-1}$ and $400 \mathrm{~nm}$

\begin{tabular}{lcc}
\hline \hline \multicolumn{1}{c}{ Material } & $\begin{array}{c}\text { IR absorbance }\left(\times 10^{4}\right) \\
\left(3470 \mathrm{~cm}^{-1}\right)\end{array}$ & $\begin{array}{c}\text { UV-vis absorbance }\left(\times 10^{4}\right) \\
(400 \mathrm{~nm})\end{array}$ \\
\hline PC & 6.1 & 14.1 \\
$A 100$ & 5.3 & 11.6 \\
Z50 & 2.4 & 8.9 \\
Z100 & 2.1 & 8.1 \\
Z50A50 & 1.4 & 3.2 \\
A50Z50 & 0.9 & 2.1 \\
A50Z50A50 & 0.8 & 2.0 \\
Z600 & 0.2 & 0.2 \\
\hline \hline
\end{tabular}

The two-layer coatings exhibited lower degradation rates than the single-layer coatings of the same total thickness (i.e., $100 \mathrm{~nm}$ ). A better protection was obtained with the $\mathrm{Al}_{2} \mathrm{O}_{3} / \mathrm{ZnO}$ coating than the $\mathrm{ZnO} / \mathrm{Al}_{2} \mathrm{O}_{3}$ coating. This can be attributed to the $\mathrm{Al}_{2} \mathrm{O}_{3}$ layer that prevented the photocatalytic effect, which is partly responsible for the degradation of $\mathrm{PC}$ at the interface with the $\mathrm{ZnO}$ layer. Hence, the $\mathrm{Al}_{2} \mathrm{O}_{3} / \mathrm{ZnO}$ coating provided greater protection against photodegradation because it combined the absorption characteristics of $\mathrm{ZnO}$ in the UV-vis range and the capacity of $\mathrm{Al}_{2} \mathrm{O}_{3}$ to block the oxygen without causing a photocatalytic effect at the PC interface. Even greater enhancement of the photo-oxidation resistance was obtained with the $\mathrm{Al}_{2} \mathrm{O}_{3} / \mathrm{ZnO} / \mathrm{Al}_{2} \mathrm{O}_{3}$ coating. This is attributed to the decrease of the oxygen diffusing through the top $\mathrm{Al}_{2} \mathrm{O}_{3}$ layer. Despite the fact that the improvement was not proportional to the increase of the coating thickness, the enhancement of the surface nanomechanical properties obtained with the threelayer coating was significant, as shown in the following section.

\section{B. Nanomechanical properties}

Figure 5 shows a typical nanoindentation curve of PC coated with a 50-nm-thick $\mathrm{ZnO}$ coating. The change in the slope of the loading curve at a displacement of $\sim 7 \mathrm{~nm}$ indicates a transition from $\mathrm{ZnO}$ - to $\mathrm{PC}$-dominated deformation behavior. It is well known that the substrate effect on the

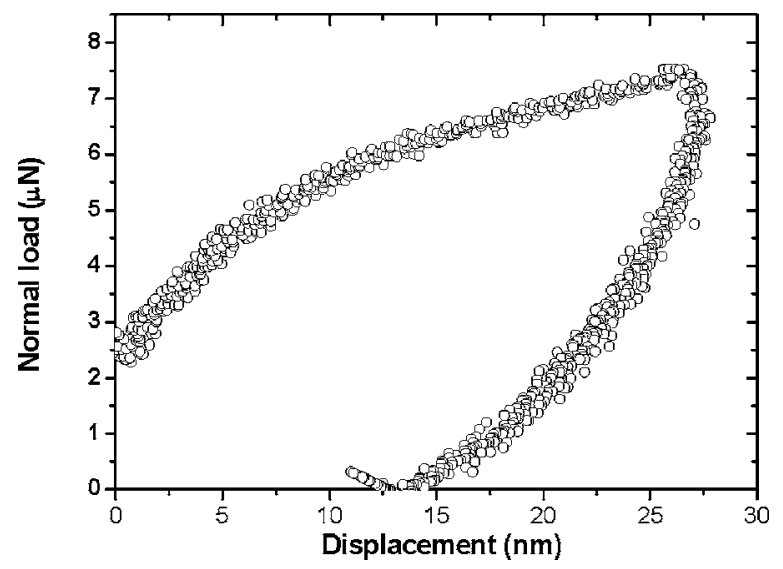

FIG. 5. Nanoindentation curve of PC with a 50-nm-thick $\mathrm{ZnO}$ coating obtained with a Berkovich diamond tip of nominal radius of curvature equal to $\sim 117 \mathrm{~nm}$. 


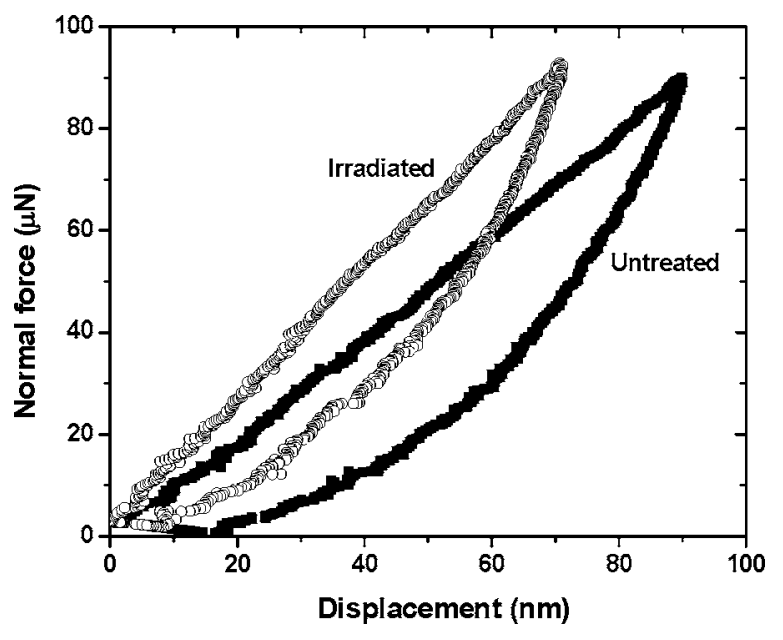

FIG. 6. Nanoindentation curves of untreated and irradiated (for $200 \mathrm{~h}$ ) PC obtained with a conospherical diamond tip of nominal radius of curvature equal to $\sim 850 \mathrm{~nm}$.

measurement of the coating mechanical properties (e.g., reduced elastic modulus and hardness) becomes more pronounced with the increase of the indentation depth. For a substrate softer and more compliant than the coating, the maximum indentation depth must be less than $\sim 10 \%$ of the coating thickness to avoid biasing of the measurements by the substrate. ${ }^{17}$ The displacement at which the loading slope decreased is equal to $\sim 14 \%$ of the coating thickness. While the condition for negligible substrate effect provides an upper bound for the maximum indentation depth, performing shallow indentations (e.g., less than $10 \mathrm{~nm}$ in depth) to avoid the substrate effect is often complicated by contact instabilities that prevent the accurate determination of the mechanical properties of a thin coating. The unloading response is characterized by the elastic unloading behavior of the stiff $\mathrm{ZnO}$ coating and the viscoelastic PC substrate. Thus, calculation of the reduced elastic modulus from the slope of the unloading curve at the maximum load and the hardness based on the tip-shape area corresponding to the maximum load is complicated by the simultaneous contributions of the coating and the substrate materials, which exhibit distinctly different deformation behaviors. The residual depth after full unloading and the relatively large hysteresis in the loaddisplacement response indicate that inelastic deformation played a dominant role in the overall mechanical response.

To examine the dependence of the deformation behavior on photo-oxidation, nanoindentations were performed on uncoated PC before and after $200 \mathrm{~h}$ of irradiation. Figure 6 shows a comparison of the nanoindentation responses of untreated and irradiated PC for the same maximum load. It can be seen that irradiation increased the slope of the loading curve and decreased the area of the load-displacement hysteresis. Statistical analysis of the data collected from more than 20 nanoindentation experiments showed that the reduced elastic modulus and hardness (defined as the ratio of the maximum load to the corresponding tip-shape area) of the untreated PC were 5.01 $\pm 0.22 \mathrm{GPa}$ and $0.46 \pm 0.06 \mathrm{GPa}$, while those of the irradiated PC were $5.10 \pm 0.32 \mathrm{GPa}$ and $0.53 \pm 0.13 \mathrm{GPa}$, respectively. These measurements reveal a small modification of the nanomechanical properties by irra-

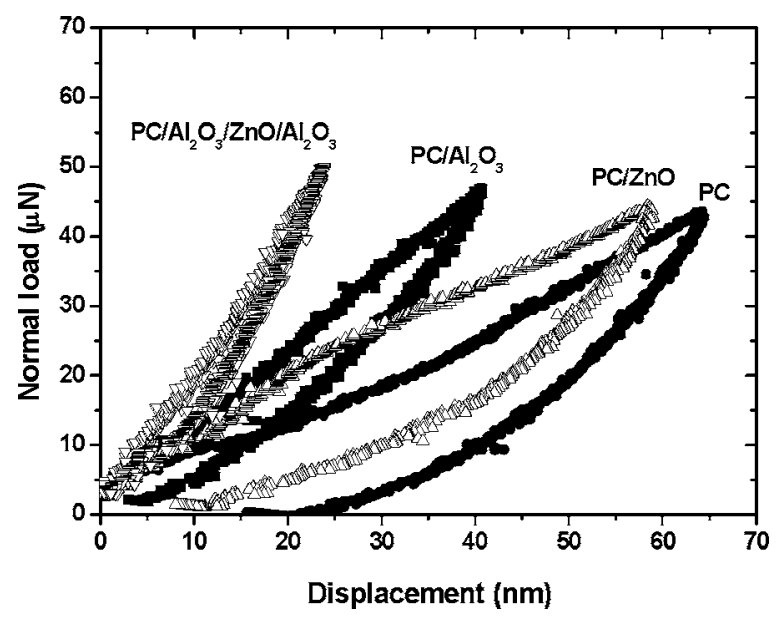

FIG. 7. Nanoindentation curves of $\mathrm{PC}$ with and without single-layer ( $\mathrm{ZnO}$ and $\left.\mathrm{Al}_{2} \mathrm{O}_{3}\right)$ and three-layer $\left(\mathrm{Al}_{2} \mathrm{O}_{3} / \mathrm{ZnO} / \mathrm{Al}_{2} \mathrm{O}_{3}\right)$ coatings obtained with a conospherical diamond tip of nominal radius of curvature equal to $\sim 850 \mathrm{~nm}$. The thickness of each layer is equal to $50 \mathrm{~nm}$.

diation. Similarly, nanoindentation experiments performed with PC samples that were physically aged at room temperature for approximately six months demonstrated an increase in both the elastic modulus and the hardness. ${ }^{18}$ Physical aging is a molecular relaxation process leading to an equilibrium state at elevated temperatures (e.g., annealing) ${ }^{19,20}$ or room temperature, even if the glass transition temperature of the polymer is higher than the ambient temperature. ${ }^{21}$ It has been suggested that densification of PC by chain reorientation increases both the elastic modulus and the hardness. ${ }^{18}$ It is likely that the accelerated conditions of photo-induced aging promoted material densification through the rearrangement of the molecular chains. Moreover, photo-Fries reactions also involve chemical rearrangement. Photo-oxidation produces oxidized groups (e.g., hydroperoxydes, alcohols, and carboxylic acids) in high concentrations close to the surface. ${ }^{1}$ These groups are associated with hydrogen bonds that may augment cohesion. Thus, physical aging, photoFries rearrangement, and/or hydrogen bonding improved the nanomechanical properties of the PC surface.

Figure 7 shows representative nanoindentation responses of $\mathrm{PC}, \mathrm{PC} / \mathrm{ZnO}, \mathrm{PC} / \mathrm{Al}_{2} \mathrm{O}_{3}$, and $\mathrm{PC} / \mathrm{Al}_{2} \mathrm{O}_{3} / \mathrm{ZnO} / \mathrm{Al}_{2} \mathrm{O}_{3}$ material systems for the same testing conditions. The residual displacement and hysteresis area illustrate the resistance against inelastic deformation. The results show that the greatest protection to the $\mathrm{PC}$ substrate was obtained with the $\mathrm{Al}_{2} \mathrm{O}_{3} / \mathrm{ZnO} / \mathrm{Al}_{2} \mathrm{O}_{3}$ coating followed by the $\mathrm{Al}_{2} \mathrm{O}_{3}$ and the $\mathrm{ZnO}$ coatings. The very small hysteresis area produced with the three-layer coating suggests that deformation was predominantly elastic. The nanoindentation curves of these coatings obtained after a $200 \mathrm{~h}$ exposure to the present irradiation conditions did not reveal any discernible differences compared to those shown in Fig. 7. This implies a negligible effect of photo-oxidation on the nanomechanical properties of the sputtered single- and multi-layer ceramic coatings.

\section{Nanotribological properties}

To determine the dependence of the coefficient of friction of each material system on the applied contact load, 


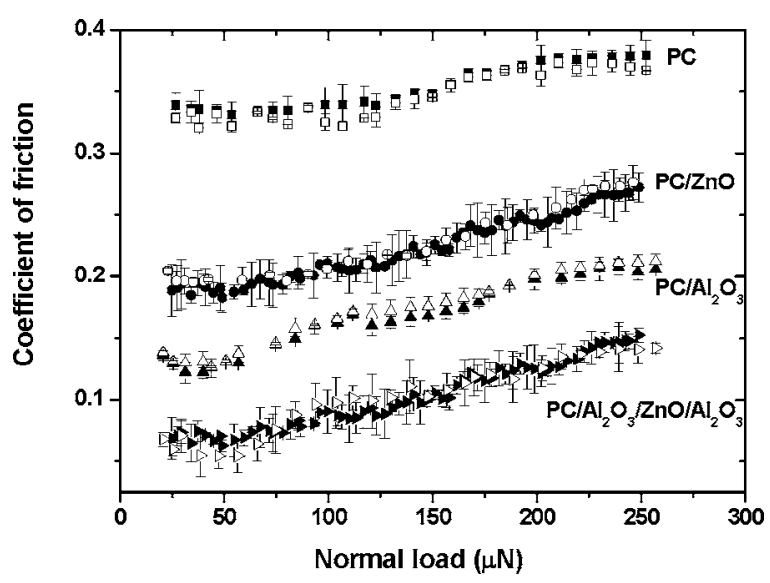

FIG. 8. Coefficient of friction versus normal load for PC ( $\square$ ), PC/ZnO ( ) $\mathrm{PC} / \mathrm{Al}_{2} \mathrm{O}_{3}(\boldsymbol{\Delta})$ and $\mathrm{PC} / \mathrm{Al}_{2} \mathrm{O}_{3} / \mathrm{ZnO} / \mathrm{Al}_{2} \mathrm{O}_{3}(\boldsymbol{\Delta})$ material systems before (filled symbols) and after $200 \mathrm{~h}$ of irradiation (open symbols) obtained with a conospherical diamond tip of nominal radius of curvature equal to $\sim 850 \mathrm{~nm}$

sliding experiments were performed in which the normal load was increased linearly. Figure 8 shows statistical results of the coefficient of friction versus normal load. The data represent mean values calculated from three experiments for each system. The error bars denote one standard deviation above and below the corresponding mean values. The lowest coefficients of friction correspond to the $\mathrm{PC} / \mathrm{Al}_{2} \mathrm{O}_{3} / \mathrm{ZnO} / \mathrm{Al}_{2} \mathrm{O}_{3}$ system and the highest to PC. The dominant deformation mode was plowing by the diamond tip. The trend revealed by the friction results shown in Fig. 8 can be interpreted in terms of the surface hardness. The significantly higher hardness of the $\mathrm{Al}_{2} \mathrm{O}_{3}$ layer reduced the contribution of plowing to the total friction force, ${ }^{22}$ resulting in a lower coefficient of friction. The coefficients of friction of the coated PC media increased almost linearly and at the same rate with the increase of the normal load, whereas the load effect on the friction coefficient of the uncoated PC was relatively marginal. The high coefficient of friction of $\mathrm{PC}$ was due to excessive plowing of the soft polymer surface by the hard diamond tip. It was found that irradiation did not influence the coefficient of friction of both coated and uncoated PC, even for sliding under light loads. This indicates that the chemical processes responsible for the photodegradation of the polymer exhibited a secondary effect on the tribological properties of the ceramic coatings, and their adhesion to the PC substrate was not degraded as a result of interfacial photo-oxidation. For example, despite the photocatalytic oxidation at the $\mathrm{PC} / \mathrm{ZnO}$ interface, delamination along the interface leading to the removal of the $\mathrm{ZnO}$ coating did not occur even under the highest normal load applied in the sliding experiments.

\section{CONCLUSIONS}

The efficacy of relatively thin ceramic coatings to reduce photodegradation and enhance the surface nanomechanical properties of PC was evaluated in the context of IR and $\mathrm{UV}$-vis spectroscopy results and measurements of the nanomechanical properties obtained with a surface force apparatus. It was shown that a thin $\mathrm{ZnO}$ coating is effective in reducing the photodegradation rate of $\mathrm{PC}$ because of the UV screening effect. However, the efficiency of the thin $\mathrm{ZnO}$ coating is limited by the photocatalytic activity at the interface with the PC substrate. The deposition of a thin $\mathrm{Al}_{2} \mathrm{O}_{3}$ layer between the $\mathrm{ZnO}$ layer and the $\mathrm{PC}$ substrate increased the resistance to photodegradation by suppressing the evolution of photocatalyzed degradation at the polymer interface. In addition, the $\mathrm{Al}_{2} \mathrm{O}_{3}$ and $\mathrm{ZnO}$ layers played the role of oxygen barriers, limiting the effect of oxidative degradation due to photoinduced aging. A higher photooxidation resistance was obtained with the three-layer coating $\left(\mathrm{Al}_{2} \mathrm{O}_{3} / \mathrm{ZnO} / \mathrm{Al}_{2} \mathrm{O}_{3}\right)$ than the two-layer coatings $\left(\mathrm{Al}_{2} \mathrm{O}_{3} / \mathrm{ZnO}\right.$ and $\left.\mathrm{ZnO} / \mathrm{Al}_{2} \mathrm{O}_{3}\right)$ because of the increase of the oxygen impermeability with the coating thickness.

The significant improvement of the surface resistance to plastic deformation and the decrease of the coefficient of friction was another benefit obtained with the three-layer coating. Prolonged irradiation of PC increased both the elastic modulus and the hardness despite the occurrence of chain scission, presumably due to the rearrangement of the chain molecules under the simultaneous effects of irradiation and heating, in conjunction with the formation of new oxidized functionalities associated with hydrogen bonding. The ceramic coatings not only protected PC from photodegradation but also enhanced the nanomechanical properties and lowered the coefficient of friction. The three-layer coating exhibited the lowest coefficient of friction over the entire load range investigated. Contrary to $\mathrm{PC}$, the similar nanomechanical properties obtained before and after extensive irradiation indicated that photochemical reactions at the polymer interface were not detrimental to the adhesion of the $\mathrm{Al}_{2} \mathrm{O}_{3}$ and $\mathrm{ZnO}$ layers to the $\mathrm{PC}$ substrate. The results of this study demonstrate that thin ceramic coatings are effective inhibitors of the photochemical reactions and deformation processes occurring in polymers, which lead to accelerated photodegradation, high friction, and excessive wear.

\section{ACKNOWLEDGMENT}

The last author would like to acknowledge the partial funding provided for this work by the National Science Foundation under Grant No. DMI-0201551.

${ }^{1}$ A. Rivaton, Polym. Degrad. Stab. 49, 163 (1995).

${ }^{2}$ A. Rivaton, B. Mailhot, J. Soulestin, H. Varghese, and J.-L. Gardette, Polym. Degrad. Stab. 75, 17 (2002).

${ }^{3}$ A. Rivaton, B. Mailhot, J. Soulestin, H. Varghese, and J.-L. Gardette, Eur. Polym. J. 38, 1349 (2002).

${ }^{4}$ N. S. Allen, J.-L. Gardette, and J. Lemaire, Polym. Photochem. 3, 251 (1983).

${ }^{5}$ B. Claudé, L. Gonon, V. Verney, and J.-L. Gardette, Polym. Test. 20, 771 (2001).

${ }^{6}$ S. Ben Amor, G. Baud, M. Jacquet, and N. Pichon, Surf. Coat. Technol. 102, 63 (1998).

${ }^{7}$ S. Giancaterina, S. Ben Amor, G. Baud, J.-L. Gardette, M. Jacquet, C. Perrin, and A. Rivaton, Polymer 43, 6397 (2002).

${ }^{8}$ A. Moustaghfir, E. Tomasella, A. Rivaton, B. Mailhot, M. Jacquet, J.-L. Gardette, and J. Cellier, Surf. Coat. Technol. 180\&181, 642 (2004).

${ }^{9}$ G. Penot, R. Arnaud, and J. Lemaire, Angew. Makromol. Chem. 117, 71 (1983).

${ }^{10}$ H. G. Völz, G. Kaempf, G. H. Fitzky, and A. Klaeren, ACS Symp. Ser. 151, 163 (1981)

${ }^{11}$ R. B. Cundall, B. Hulme, R. Rudham, and M. S. Salim, J. Oil Col. Chem. Assoc. 61, 351 (1978) 
${ }^{12}$ A. Moustaghfir, A. Rivaton, E. Tomasella, B. Mailhot, J. Cellier, M. Jacquet, and J.-L. Gardette, J. Appl. Polym. Sci. 95, 380 (2005).

${ }^{13}$ P. Gauvin, J. Lemaire, and D. Sallet, Makromol. Chem. 188, 971 (1987).

${ }^{14}$ A. Rivaton and J. Lemaire, Polym. Degrad. Stab. 23, 51 (1988).

${ }^{15}$ G. M. Pharr, W. C. Oliver, and F. R. Brotzen, J. Mater. Res. 7, 613 (1992).

${ }^{16}$ X.-G. Ma, K. Komvopoulos, D. Wan, D. B. Bogy, and Y.-S. Kim, Wear 254, 1010 (2003).

${ }^{17}$ W. Lu and K. Komvopoulos, J. Tribol. 123, 641 (2001).
${ }^{18}$ V. A. Soloukhin, J. C. M. Brokken-Zijp, O. L. J. van Asselen, and G. de With, Macromolecules 36, 7585 (2003).

${ }^{19}$ A. J. Hill, K. J. Heater, and C. M. Agrawal, J. Polym. Sci., Part B: Polym. Phys. 28, 387 (1990).

${ }^{20}$ J. M. Hutchinson, S. Smith, B. Horne, and G. M. Gourlay, Macromolecules 32, 5046 (1999).

${ }^{21}$ N. Heymans, Polymer 38, 3435 (1997).

${ }^{22}$ K. Komvopoulos, N. Saka, and N. P. Suh, J. Tribol. 108, 301 (1986). 